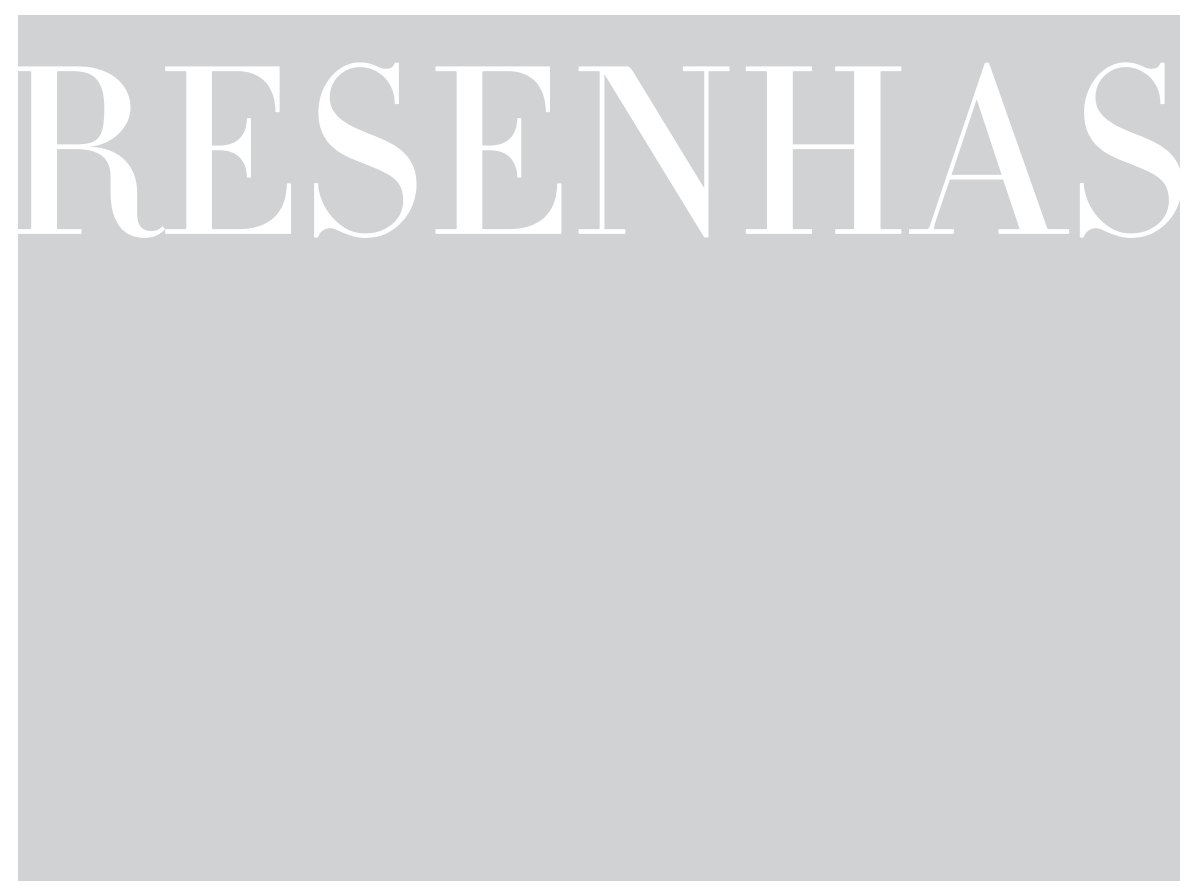

\title{
AS CIÊNCIAS HUMANAS SERVEM PARA ALGUMA COISA?
}

ORDINE, Nuccio. A utilidade do inútil: um manifesto. Tradução de Luiz Carlos Bombassaro. Rio de Janeiro: Zahar, 2016.

No universo do utilitarismo, um martelo vale mais que uma sinfonia, uma faca mais que um poema, uma chave de fenda mais que um quadro: porque é fácil compreender a eficácia de um utensílio, enquanto é sempre mais difícil compreender para que podem servir a música, a literatura ou a arte (p. 12)

Provavelmente, todo estudante ou profissional ligado às ciências humanas, em algum momento, foi questionado sobre o sentido de sua atividade, ou melhor, sobre a "utilidade" de seu ofício. Nada mais justo, pois os contribuintes evidentemente têm interesse em saber os motivos para financiar atividades não ligadas diretamente à produção. Artes, filosofia, história, geografia, literatura, entre uma série de outros campos do saber, contribuem em alguma medida para a sociedade? Não seria mais prudente alocar os recursos dessas áreas para a formação de técnicos, engenheiros, médicos, tidos como criadores de conhecimentos e práticas "úteis"? Tais formas de pensar, tão difundidas em diversas regiões do planeta hoje em dia, guardam semelhança com uma série de questionamentos surgidos em outros períodos e épocas. Da mesma forma, uma série de respostas contrárias a elas foi formulada e divulgada ao 
longo dos séculos, inclusive por notáveis pensadores. Esse é justamente o tema do importante livro A utilidade do inútil: um manifesto, de Nuccio Ordine, lançado na Itália em 2013 e publicado este ano no Brasil.

Filósofo de formação e professor de literatura na Universidade da Calábria, Ordine é um renomado especialista no período do Renascimento, especialmente em Giordano Bruno. Entre algumas de suas obras, estão 0 umbral da sombra (Perspectiva, 2009), A cabala do asno (Educs, 2006) e Contro Il Vangelo armato (2009). No livro resenhado aqui, bastante politizado, como admite o autor e indica seu subtítulo, avulta o pano de fundo de uma Europa, com a exceção da Alemanha, cada vez mais ciosa de investir em cultura e artes diante do turbilhão econômico. O leitor brasileiro, entretanto, não terá nenhuma dificuldade em identificar semelhanças com o caso brasileiro, de tradição de parcos investimentos nessas áreas, os quais, aliás, são constantemente cortados sob o questionamento de sua "utilidade" - sem contar a diminuição da presença das disciplinas humanísticas nos currículos escolares. Em contraposição a tudo isso, Ordine indica como as artes e o pensamento humanístico, num paradoxo apenas aparente, são de importância crucial ou "úteis" não apenas para a prosperidade material, como também para a defesa de uma vida minimante civilizada nas mais diversas sociedades. Não se trata de obra sistemática, como ele próprio afirma, mas de recortes de obras de grandes autores por ele acumulados ao longo de sua carreira, acompanhados de seus comentários. De forma geral, tratase de defender a utilidade "daqueles saberes cujo valor essencial está completamente desvinculado de qualquer fim utilitarista” (p. 9).

Um primeiro passo nesse sentido é afirmar que os saberes inúteis podem oferecer uma resistência à noção de utilidade dominante, a qual está destruindo a memória do passado, as disciplinas humanísticas, as línguas clássicas, a educação, a livre pesquisa, a fantasia, a arte, o pensamento crítico, a dignitas hominis, o amor e a verdade. Ordine nunca chega a nomear ou conceituar a orientação política subjacente a essas transformações. No entanto, o cerne da crítica volta-se contra a corrente neoliberal de pensamento e ação. Gostemos ou não desse termo, sem dúvida carregado de paixões na luta política, ele ao menos aponta para uma orientação política voltada para a diminuição drástica do papel do Estado na economia e a concorrência acirrada entre os indivíduos, com seu corolário de valorização extrema das posses materiais. Na contracorrente, Ordine argumenta que o saber desinteressado é um instrumento capaz de se opor às leis do mercado, na medida em que, ao desafiar os princípios dominantes do lucro, pode ser compartilhado sem empobrecer quem o transmite e quem o recebe; resultando, ao contrário, em enriquecimento mútuo.

Na primeira parte do livro, o autor discute algumas partes da obra de notáveis escritores e poetas, de modo a sugerir o papel da literatura na 
desnaturalização das mais diversas formas de utilitarismo. Um exemplo muito significativo é o de uma passagem das Cartas a um poeta, de Rainer Maria Rilke. Nela, este assevera que ser artista "não significa calcular e contar, mas sim amadurecer como a árvore, que não apressa a sua seiva e enfrenta tranquila as tempestades da primavera, sem medo de que depois dela não venha nenhum verão” (p. 18). Em geral, nada mais distante do contexto universitário atual, que, em escala global, submete disciplinas com forte teor artístico ao ritmo da produção fabril, à ética do publish or perish. Em artigo de grande relevância, Claudine Haroche igualmente destaca que o trabalho de pensamento requer tempos mortos, momentos inúteis, pausas: tarefa a ser realizada pelas pessoas em sua condição de indivíduos, em sua parte inavaliável (HAROCHE, 2011, p. 675). Contudo, no contexto contemporâneo, as avaliações constantes e dos mais variados tipos comprometem profundamente o juízo crítico e a reflexão. A competição exacerbada das sociedades neoliberais e o alto grau de desconfiança interpessoal por elas engendrado produzem mecanismos de controle que, sob o princípio da eficiência, atingem em cheio a autonomia intelectual (HAROCHE, 2011, p. 661). Nesse sentido, Ordine pensa que clássicos da literatura podem sugerir lógicas e caminhos alternativos ao difundido utilitarismo dos dias atuais.

Em sua opinião, as atividades consideradas supérfluas propiciam não apenas a crítica a tal tendência, como também oportunidades para se cultivar horizontes utópicos. Por exemplo, nas obras de Thomas More, Tommaso Campanella e Francis Bacon, o dinheiro, o ouro, a prata e todas as atividades destinadas ao ganho são desprezadas. Nas célebres ilhas imaginárias construídas por esses intelectuais, toda forma de propriedade individual é atacada, em favor do interesse coletivo. Para Ordine, tais reflexões podem ser estímulos para se pensarem modos de combater as desigualdades sociais do mundo contemporâneo. É claro que tal potencial existe e deve ser levado em consideração. Como contraponto, talvez valha a pena lembrar que as atividades supostamente irrelevantes também podem engendrar ideias voltadas para a perpetuação dos referidos desequilíbrios. Não há um caminho único. De qualquer forma, eliminá-las significaria comprometer a busca de caminhos alternativos.

No livro, os exemplos de pensadores que se colocaram, ao longo de diversas épocas e em diferentes localidades, contra a associação entre conhecimento e ganho material são abundantes: Aristóteles, Dickens, Boccaccio, Baudelaire, Kant, Montaigne, Lorca, Cervantes, o sábio chinês Zhuangzi, entre outros. No caso de Dante e Petrarca, tais autores criticavam severamente a vinculação das letras a objetivos ligados ao acúmulo monetário; prezando, ao contrário, o amor desinteressado pela sabedoria. É de se perguntar se esse pressuposto está ligado a um ethos medieval contrário à comercialização do conhecimento, conforme 
expresso no seguinte aforismo: "O conhecimento é um dom de Deus, e por isso não pode ser vendido” (BURKE, 2003, p. 136). Só um estudo aprofundado poderia fornecer uma resposta satisfatória a essa questão. De todo modo, é importante ressaltar que não é possível estabelecer uma essência para a noção de utilitarismo, como parece fazer Ordine. As respostas dos referidos autores à presença do ganho material em seu ofício parecem estar vinculadas a problemas específicos das sociedades e épocas nas quais cada um viveu. Em suma, elas são historicamente construídas; porém, certamente, releram ou reinventaram tradições críticas de épocas anteriores.

Algo parecido acontece com os defensores da "utilidade" dos conhecimentos. Um marco dessa corrente de pensamento é, sem dúvida, John Locke, um contraexemplo de Ordine. Em sua obra Alguns pensamentos sobre a educação (1693), ele criticou fortemente a imposição do estudo de versos a estudantes apáticos com o objetivo de torná-los modestos produtores de rimas. Ademais, atacou os pais que permitiam aos seus filhos cultivar o talento poético, em detrimento da busca pelo crescimento dos bens pessoais; segundo Ordine, argumentos tão semelhantes por ele ouvidos da parte de muitos dos pais de seus alunos: "Mas o que o meu filho vai fazer com um diploma de Letras?”. Nada casual, em se tratando de um autor central para a releitura do liberalismo hoje em dia.

A segunda parte do livro é dedicada a críticas contundentes ao contexto universitário europeu. Num momento de amplo corte de verbas para a educação e a pesquisa, o filósofo italiano considera que muitas universidades europeias se tornaram ou estão se tornando verdadeiras empresas. Não só pelo fato de tratarem os alunos como clientes, a exemplo do que acontece nos Estados Unidos e no Canadá, como também em razão de produzirem diplomados em massa sem uma suposta devida qualidade. Em sua opinião, a tendência tem sido tornar as aulas mais superficiais, com o argumento de deixá-las mais “agradáveis”; e os métodos de avaliação não exigiriam grandes esforços dos estudantes. Tal crítica mereceria um cuidado especial, pois - ainda que seja desejável buscar sempre o aprofundamento daquilo que se ensina -, um endurecimento irrefletido das práticas pedagógicas, em determinados contextos e situações, não poderia levar justamente ao esvaziamento das salas de aula e à elitização do ensino?

Entretanto, muito pertinente é a sua crítica à burocratização dos professores universitários. Preencher formulários, fazer relatórios para alimentar as estatísticas, preparar projetos para obter escassos recursos, participar de intermináveis assembleias e reuniões de colegiado, eis as tarefas que consomem a maior parte do tempo desses profissionais, cada vez menos providos de tempo para exercer sua curiositas na pesquisa e no ensino - os professores universitários brasileiros passam por drama semelhante, provavelmente mais grave. Em contraposição, Ordine 
lembra que centros de excelência em pesquisa foram fundados sob o princípio da busca desinteressada de conhecimento, como o Collège de France e o Instituto de Estudos Avançados de Princeton. Neste último caso, o autor comenta o texto do pedagogo norte-americano Abraham Flexner, de 1937, um dos mais importantes fundadores do Instituto - belo artigo anexado ao final do livro. Idealizado como centro distante de fins utilitaristas, tal instituição abrigou nomes como o de Albert Einstein. Ademais, como argumenta Flexner sobre os fundamentos que deveriam nortear o Instituto, inventos outrora considerados como despidos de utilidade, como as ondas eletromagnéticas descobertas e analisadas por James Clerk Maxwell e Heinrich Hertz (supostamente sem motivações práticas), teriam o potencial de se tornarem tecnologias de uso tido universalmente como essencial, a exemplo do rádio. Seria de se questionar se as vidas humanas, em geral e de acordo com circunstâncias histórias específicas, comportam tamanha pureza em seus idealismos; não seriam elas, ao contrário, palco de constante tensão entre idealismos e objetivos utilitaristas? Se essa hipótese tiver algum fundamento, o que se deveria lamentar, nos últimos tempos, é a crescente sobreposição dos últimos sobre os primeiros.

Mas como, em tempos de crise, criar condições distanciadas do utilitarismo para que o conhecimento floresça e frutifique? Ordine chega a ser autoritário nesse ponto, pois advoga que "seria necessário impor" um discurso proferido por Victor Hugo na Assembleia Constituinte francesa, em 1848, aos membros dos governos europeus. Uma outra forma de abordar a questão, a meu ver, seria apontar que o referido texto poderia ser mais frequentemente mencionado no debate público. No discurso, o célebre escritor, na iminência de que os ministros cortassem recursos destinados à cultura, inflama-se ao defender que, exatamente no momento em que uma crise sufoca uma nação, é preciso duplicar os recursos voltados para o saber e o ensino, a fim de impedir que a sociedade seja tragada pela ignorância. Em outras palavras, esta última é colocada em condição inferior àquela das necessidades materiais.

Num cenário em que se questiona o ensino das línguas clássicas, da filologia, da paleografia, em que as obras clássicas são cada vez menos publicadas pelas editoras, em que museus e bibliotecas são fechados, em franca ameaça à memória, as palavras de Victor Hugo têm muito a dizer. Por sua vez, os saberes humanísticos, a literatura e a educação, segundo Ordine, podem contribuir para o desenvolvimento das ideias de democracia, liberdade, justiça, laicidade, igualdade, direito à crítica, tolerância, solidariedade e bem comum. Eis a utilidade do inútil. O livro em questão, mesmo que simplifique algumas questões, levanta problemas de fundamental importância para o debate público em diferentes sociedades, não sendo casual o fato de já ter sido traduzido para várias línguas. No Brasil, ele é publicado no turbilhão de uma crise econômica 
e política, em meio à qual, sem entrar neste momento nas questões da legitimidade ou ilegitimidade do atual governo, drásticos cortes de gasto na educação e na cultura estão sendo colocados em marcha. Dessa forma, sua leitura é recomendada não apenas a estudantes, acadêmicos e educadores, como também aos políticos e eleitores em geral.

\section{REFERÊNCIAS}

BURKE, Peter. Uma história social do conhecimento: de Gutenberg a Diderot. Rio de Janeiro: Zahar, 2003.

HAROCHE, Claudine. O inavaliável em uma sociedade de desconfiança. Educação e Pesquisa, São Paulo, v. 37, n. 3, p. 657-676, set./dez. 2011. Disponível em: <http://www.scielo.br/scielo. php?script=sci_arttext\&pid=S1517-97022011000300014>. Acesso em: maio 2016.

\section{JEFFERSON JOSÉ QUELER}

Doutor em História pela Universidade Estadual de Campinas - Unicamp -, Campinas, São Paulo, Brasil; professor adjunto do Departamento de História da Universidade Federal de Ouro Preto - Ufop -, Ouro Preto, Minas Gerais, Brasil jeffqueler@hotmail.com 